\title{
REFLEXÕES ACERCA DAS NOVAS DIRETRIZES CURRICULARES NACIONAIS NA FORMAÇÃO DO ENGENHEIRO CIVIL
}

\author{
Hevêncio Henrique Coelho Dias - hevencio_coelho@hotmail.com \\ Universidade Federal de Santa Maria \\ Avenida Roraima, 1000 \\ 97105-900 - Santa Maria - Rio Grande do Sul
}

Gihad Mohamad-gihad@ufsm.br

Universidade Federal de Santa Maria

Avenida Roraima, 1000

97105-900 - Santa Maria - Rio Grande do Sul

\begin{abstract}
Resumo: As Novas Diretrizes Curriculares Nacionais (DCN's) de Engenharia estabelecidas em 2019, propõe uma mudança de paradigma para a formação do discente, migrando de um sistema de ensino que buscava uma formação generalista, para uma formação holística, a qual pressupõe uma compreensão mais profunda do produto que é desenvolvido pelo Engenheiro através de projetos. As novas DCN's promove um egresso com grande formação técnica e com uma atuação dinâmica e com uma formação continuada, capaz de lidar com um mercado de trabalho eficiente promovendo inovações sustentáveis. Nessa nova realidade de formação, percebe-se que tecnologias que já estavam em voga como por exemplo a utilização da plataforma BIM e a adoção de novos materiais passam a estarem alinhadas as demandas da indústria da construção civil por mais produtividade e a uma consciência coletiva que requer sustentabilidade e responsabilidade social. Convergindo assim a formação de um profissional com autonomia intelectual e consciente do impacto social, econômico, político e ambiental no seu exercício profissional.
\end{abstract}

Palavras-chave: Inovação e Sustentabilidade. Diretrizes Curriculares. Engenharia.

\section{INTRODUÇÃO}

Em um contexto marcado pela polarização no discurso político, frente a vários aspectos da vida coletiva, tal como a democracia, a resistência quanto a relevância do conhecimento científico, no passo em que o mundo perpassa uma pandemia causada pelo vírus COVID-19, que traz consigo, além de uma crise sanitária, uma crise econômica e uma ressignificação da relação do indivíduo com o mundo, e principalmente da atuação profissional, cabe às universidades ponderar sua atuação diante de uma transição de paradigma no modo de vida, e da sistemática em que se dá a produção de bens e serviços, tanto em decorrência de seu modo operacional, quanto ao seu alcance.

Não obstante às mudanças pragmáticas devido ao distanciamento social imposto pela pandemia, ao contexto de que nas relações políticas, no conflito de ideias e processos para a resolução de problemas se tem o menosprezo e a precarização das políticas educacionais públicas, que cerceiam o conhecimento técnico-científico e se faz oneroso ao desenvolvimento social, - segundo Accorssi, Clasen e Silveira (2019) - , surge no ambiente acadêmico a 
reformulação das Diretrizes Curriculares Nacionais de Graduação em Engenharia (DCN's), dispositivo este, o qual as escolas de Engenharia devem se embasar na estruturação de seus cursos.

Outro fator relevante a discussão, se dá ao fenômeno ao que se está sendo denominado de a quarta revolução industrial, ou indústria 4.0, que conforme o que relata Oliveira e Simões (2017), está relacionada a automação, eficiência e inovação e consiste na digitalização do trabalho industrial, que consequentemente ocasiona a " substituição do processo de produção, do homem para elementos materiais e tecnológicos", cujo objetivo é voltado para a melhoria contínua.

Portanto, encontra-se a universidade em um delicado momento de transição, e que em face das intempéries sociais, e em conformidade com a legislação e políticas públicas adotadas, se posta a refletir a respeito de sua atuação, seu processo pedagógico, sua relação com a sociedade e a formação do profissional de Engenharia que deve conter em sua expertise, autonomia intelectual, e capacidade de avaliar os problemas encontrados na sociedade, afim de conceber, elaborar e projetar soluções correlatas as especificidades de seu campo de conhecimento, caracterizado pela sua atuação técnico científica.

\section{RESOLUÇÃO N² DE 24 DE ABRIL DE 2019.}

Segundo Santana (2018), as mudanças trazidas pelas novas DCN's para os cursos de Engenharia, são oriundas da necessidade em atender um perfil de profissional mais moderno, que tem sido apontado como demanda por várias entidades, entre elas a CNI (Confederação Nacional das Indústrias) que relata carências na formação de engenheiros.

A Resolução No 2 de 24 de abril de 2019, que institui essas Diretrizes Curriculares, traz consigo, em seu capítulo II, o perfil e competências esperadas do egresso de Engenharia em âmbito nacional, e que conforme seu art. $3^{\circ}$, destaca-se:

"I - ter visão holística e humanitária, ser crítico, reflexivo, criativo, cooperativo e ético e com forte formação técnica;

II - estar apto a (...) adaptar e utilizar novas tecnologias, (...);

IV - adotar perspectivas multidisciplinares $e$ transdisciplinares em sua prática;

VI- atuar com isenção e comprometimento com a responsabilidade social e com o desenvolvimento sustentável; $"$

Portanto, afim de se fazer cumprir o que se dispõe as diretrizes, conclui-se que o ensino de engenharia migra de uma perspectiva focada em conteúdo, e passa a ter como objetivo a formação e desenvolvimento de competências, para as quais, incumbe a academia, como se específica o art. $4^{\circ}$ da resolução, de que os cursos de Engenharia proporcionem durante a formação acadêmica, competências gerais aos egressos, às quais, destaca-se:

\footnotetext{
"II - b) prever os resultados de sistemas por meio de modelos;
} 
III - conceber, projetar e analisar sistemas, produtos (bens e serviços), (...) desejáveis e viáveis, técnica e economicamente, nos contextos em que serão aplicados; IV - implantar, supervisionar, e controlar as soluções de Engenharia;

$V$ - comunicar-se eficazmente nas formas escritas, oral e gráfica:

a) ser capaz de expressar-se adequadamente (...), mantendo-se sempre atualizado em termos de métodos e tecnologias disponíveis; (...)

a) ser capaz de compreender a legislação, a ética e a responsabilidade profissional e avaliar os impactos das atividades de Engenharia na sociedade e no meio ambiente."

De acordo com Santana (2018), a reformulação das diretrizes, além de voltadas para a modernização do profissional, está alinhada com as modificações nas relações de trabalho em face do que se chama uma quarta revolução industrial, e também busca-se diminuir a evasão escolar, fenômeno característico dos cursos de Engenharia, no qual tem-se conforme Oliveira (2017) apud Santana(2018), pouco menos de 10\% das vagas ofertadas para o ensino de engenharia, resulta na formação destes profissionais.

Santana (2018) ressalta que a nova DCN fornece maior autonomia as Instituições de Ensino Superior (IES), na definição de sua carga horária, e que embora possa ser uma medida que contraria a simplicidade e objetividade que a própria Engenharia preza, volta-se a aumentar a formação do aluno, com uma aprendizagem ativa e com maior contato com experiências práticas, seja em laboratório, ou em atividades de estágio.

\section{METODOLOGIA}

Este trabalho por meio da avaliação das Novas Diretrizes Curriculares Nacionais quanto ao perfil do egresso do curso de Engenharia, e por meio da revisão bibliográfica acerca de temas considerados inovadores na indústria da construção civil, busca apontar aspectos de maior relevância para a atualização do currículo dos cursos de Engenharia Civil, conforme o que se institui a DCN, nas IES.

\section{RESULTADOS E DISCUSSÕES.}

\subsection{Da comparação entre as diretrizes de 2002 e 2019.}

Uma abordagem em que se faz vital como ponto de partida é identificar as mudanças mais significativas para as novas Diretrizes Curriculares Nacionais de 2019, em face de sua predecessora - a DCN de 2002 -, no que se limita a temática deste trabalho, com efeito, destacase que o perfil esperado do egresso na normativa anterior buscava a "formação generalista , humanista, crítica e reflexiva (...) estimulando a sua atuação crítica e criativa (...), considerando seus aspectos políticos, econômicos, sociais, ambientais e culturais".

Contudo, a reformulação expressa na nova resolução, fomenta o perfil do egresso com "visão holística e humanista", a qual se diferencia em profundidade em relação ao anterior, pois 
enquanto aquela se focava em fornecer ao indivíduo profissional de engenharia uma visão ampla dos significados de sua atuação e da abrangência de suas atribuições, enquanto que esta, se concentra em uma formação onde o sujeito pode identificar o todo e portanto compreender suas relações, fato este que é reforçado no art. $3^{\circ}$ inciso IV - adotar perspectivas multidisciplinares e transdisciplinares em sua prática, enquanto que a DCN de 2002, trazia em seu artigo $4^{\circ}$ a ideia de que a formação deste profissional dever-se-ia, lhe prover a habilidade de atuar em uma equipe multidisciplinar.

Isto acarreta uma mudança significativa, pois incumbe o profissional no seu exercício a responsabilizar-se pelas fronteiras e pelas relações com que o seu exercício e especificidade tem com outras áreas do conhecimento, não diminuindo a necessidade do trabalho em equipe, mas promovendo uma atuação mais dinâmica na resolução de problemas, o que se alinha com as transformações na relação de trabalho no mundo atual. A visão holística no exercício da Engenharia, se faz mais efetiva do que uma formação generalista, pois essa pressupõe a preparação do indivíduo a atuar de maneira mais consciente e responsável, enquanto que uma formação generalista se limita a uma compreensão geral da atividade do engenheiro e não o fornece autonomia intelectual para sua prática.

\subsection{Das tendências a serem incorporadas no processo de formação.}

O Mckinsey Global Institute (MGI) em 2017, por meio de relatório técnico, expressa a importância do setor da construção civil para a economia e o desenvolvimento social em um nível internacional, e constata a necessidade de medidas para o aumento de produtividade deste, que possui um comportamento cíclico e é dependente das demandas do setor público, afetado também pela alta informalidade, que conforme o Conselho de Arquitetura e Urbanismo (CAU) (2015), apenas $15 \%$ da população que já realizou alguma construção ou reforma, contratou um profissional de arquitetura ou engenharia.

O MGI (2017), estima que a construção civil, emprega cerca de 7\% da força de trabalho no mundo, portanto, a relevância em se discutir a formação do profissional de engenharia é necessária, para o enfrentamento dos desafios de um setor vital a economia e as relações de trabalho.

Segundo MGI (2017), o setor da construção civil em comparação com os demais setores da economia, apresenta uma estagnação em termos de produtividade, e que de acordo com Zancul et. al.(2014), no Brasil, se dá pelo aumento da complexidade nos negócios, decorrente da gestão de obras simultâneas aliadas a um cenário de baixa qualificação da mão de obra e uma restrição de recursos, tendo em vista que no período de 2007 a 2012, enquanto as empresas do setor apresentaram um aumento de $50 \%$ na sua receita, seus custos aumentaram na faixa de $60 \%$.

De acordo com Ceotto (2020), um dos erros que as incorporadoras cometem, é aperceberse do tempo como recurso, o que provoca uma noção distorcida no ciclo na gestão dos empreendimentos, fazendo com que o ciclo de negócios se estenda muito e toda vez que se tem grandes ciclos, se tem baixa produtividade. (informação verbal) ${ }^{1}$

\footnotetext{
${ }^{1}$ Fala do Eng ${ }^{\circ}$ Civil Luiz Henrique Ceotto, em transmissão no instagram, junho de 2020.
} 
Os estudos de Zancul, et. al(2014) e MGI (2017), concordam que o aprimoramento de alguns aspectos da construção civil, são de grande valia para o aumento da produtividade do setor, como por exemplo a melhoria nos processos de planejamento e execução de projetos; adoção de métodos construtivos mais eficientes; melhorias de projeto e a qualificação da mão de obra.

Zancul et al(2014), estabelece a "aplicação de software tipo BIM (building information model), como forma de se aprimorar os processos de planejamento e execução de projetos para alavancar a produtividade, o MGI (2017) aponta que implantar tecnologias digitais, tais como a utilização de modelos 3D por meio da plataforma BIM, ferramentas de colaboração digital como o uso de drones, aplicar o conceito 5D BIM que permite maior transparência no projeto e na avaliação de custos e progressos assim bem como se utilizar da chamada Internet das Coisas são estratégias válidas para o incremento de produtividade.

O relatório do MGI (2017) sugere a criação de legislações que estabelecem a utilização do BIM para se ampliar a transparência e colaboração no setor, medida esta que foi implementada no Brasil, por meio do decreto 10306, de 02 de abril de 2020, tornando a implementação do BIM de forma gradual, obrigatória na execução de obras da administração pública federal.

Zancul et. al(2014), indica que a aplicação de métodos construtivo baseados em elementos pré fabricados, alvenaria estrutural e estruturas metálicas, podem fornecer maior produtividade na indústria da construção civil, que por sua vez demandam melhorias no processo de planejamento da execução de projetos e na concepção do mesmo, donde se depara com a visão holística do processo e do produto, com a qual se enseja formar o profissional de Engenharia com as novas diretrizes curriculares.

Oliveira e Souza (2013), considera que no Brasil, as escolas de arquitetura e engenharia civil, abordam de maneira bastante aquém do necessário temas referentes a sistemas construtivos industrializados e que inclusive quando se tem a abordagem a mesma não ocorre de maneira enfática, o que deixa em segundo plano em comparação com sistemas convencionais, o que por sua vez contraria a proposta das diretrizes curriculares nacionais. Ainda conforme Oliveira e Souza, tem-se que dentre as universidades brasileiras avaliadas, apenas $2 \%$ dessas apresentam o tema destes sistemas construtivos de maneira exclusiva.

De acordo com Oliveira e Souza (2013), o setor da construção civil retrata um grande atraso em termos de produtividade e das características de seu processo industrial, o que já era descrito em meados de 1970, conforme Bender (1976), apud Oliveira e Souza (2013), e tal afirmação é reforçada nos estudos de Zancul et al (2014) e MGI (2017). Oliveira e Souza (2013) pondera que "essa realidade brasileira pode ter como uma das causas a qualidade do ensino superior de arquitetura e engenharia civil" e afirma ainda que:

\footnotetext{
"A universidade tem papel essencial (...), pois é responsável pela formação dos futuros profissionais que atuarão no mercado da construção civil. Para que se possa pensar em ampliar a utilização de sistemas construtivos industrializados no Brasil, deve-se primeiro trabalhar para que esse sistema seja difundido na base de ensino." Oliveira e Souza (2013).
} 


\subsection{Da incorporação do BIM nos currículos de Engenharia Civil.}

Carvalho et.al. (2020), relata que o ensino da Geometria Gráfica, da maneira habitual, nem sempre se faz eficiente para transmitir conceitos aos alunos e que portanto, a modelagem pode vir a aprimorar esse aspecto do processo de ensino-aprendizagem, por meio da demonstração que não seria possível no desenho 2D, através da interpretação feita e na simplificação do objeto cognoscível. Carvalho acrescenta que na perspectiva teórica do ensino-aprendizagem, quando um dado problema é abordado de uma forma unilateral, dificulta-se ao discente, percebê-lo em diferentes perspectivas, tal como é demandado para se adquirir como competência uma visão holística, agora imposta pela nova DCN.

Segundo Velasco (2010), o ensino da área gráfica - que por sua vez tem sido gradativamente fragmentado e desvalorizado, em virtude inclusive da precariedade de sua abordagem já no ensino fundamental e médio -, é de grande valia para o desenvolvimento de uma aptidão espacial para o aluno o que favorece ao mesmo variedade de estratégias de raciocínio, analíticas, verbais e lógico matemáticas, o que o ajuda a pensar na resolução de problemas.

Contudo, Velasco (2010) aponta que as reduções em termos de fundamentos técnicos, carga horária e a tendências de professores que ministram tais disciplinas por afinidade ao invés de formação específica, a falta de material didático em padrões compatíveis com às linguagens de comunicação exigida pelos novos usuários, devido à falta de demanda por atualização dos mesmos, faz com que o ensino do desenho no ensino superior seja superficial, consistindo basicamente no ensino de tópicos teóricos do desenho geométrico, enquanto que o desenho projetivo corresponde a formação da linguagem fundamental das Engenharias, e que portanto, a informática se reveste de grande importância para superar dificuldades na verbalização de problemas gráficos no processo de ensino-aprendizagem.

As noções de BIM, remontam a estudos à época, 1975, na Universidade de CarnegieMellon, onde já se procurava se introduzir interatividade na definição de elementos, e automatização no processo de projeto, fazendo com que uma mudança em uma determinada vista, fosse repassada para as demais, sem a necessidade da revisão de cada prancha, que no caso de modelos para construção são muitas, e sendo esse aspecto uma importante revolução para a forma de projetar que viria mais tarde vir a ser implantada graças ao avanço tecnológico. Eastman, et. al (2008)

Segundo Lima et. al. (2019), "o ensino de BIM deve ser visto como uma necessidade dadas as atuais exigências da indústria da construção.” De acordo com Bastos e Lordsleem (2016), essa indústria, devido sua necessidade de estimular uma maior integração entre os diversos profissionais envolvidos nos processos de projeto, planejamento e na execução de um empreendimento, estão buscando cada vez mais apropriar-se do conceito BIM em seus projetos.

"É fato que os desenhos e modelos geométricos em CAD, em muitos casos, não estão mais sendo suficientes para a representação e o gerenciamento dos projetos de empreendimentos que se tornam cada vez mais complexos. Isso se deve porque os documentos são desenvolvidos de forma independente e são apresentados separadamente, em grande parte por profissionais projetistas de 
especialidades distintas em escritórios de projetos que não compartilham as informações de seus projetos durante o desenvolvimento." Bastos e Lordsleem, (2016)

Vale ressaltar que ao se discutir o exercício do profissional de engenharia e inclusive de arquitetura, por vezes, se suprime a necessidade de expressão por meio do desenho manual, que embora seja válido como estratégia de formação do mesmo, não é mais incorporado à atividade destes, vistos que até mesmo dispositivos legais, como códigos de obras e edificações, por vezes, a exemplo da lei complementar no 118-2018 de Santa Maria - Rio Grande do Sul estabelecem a entrega de documentos para expedição de licenças e habite-se, com seus projetos realizados por meio do CAD.

Conforme Lima et.al. (2019), a restrição de carga horária nos cursos de Engenharia Civil, para satisfazer todos os critérios e conteúdos característicos representa uma dificuldade para inserir conteúdos relacionados ao BIM nas grades curriculares, e que, portanto, sugere a adoção integrado do ensino do BIM, diluindo-o nas ementas das disciplinas. Abordagem esta que se mostra totalmente alinhada com os preceitos das Diretrizes Curriculares Nacionais de 2019, e satisfaz inclusive a interpretação do que é a plataforma BIM, que para Ceotto (2020), é mais do que um sistema de projeto, é uma plataforma de integração de informação. (informação verbal) ${ }^{2}$

Portanto, considera-se que devido a característica intrínseca do BIM, que se faz presente em todo ciclo de um empreendimento, da sua concepção, à sua execução, manutenção até a demolição, abrangendo as diversas disciplinas de projeto, como arquitetônico, estrutural e de instalações, sendo também por meio da plataforma BIM 5D, na qual se faz possível a análise de custos e programação da edificação, torna este conceito alinhado com o perfil almejado de um egresso de Engenharia Civil segundo às novas DCN's, com as necessidades tanto de integração de conteúdo para uma formação mais holística, multidisciplinar e transdisciplinar, quanto para o exercício profissional mais dinâmico.

\section{CONSIDERAÇÕES FINAIS}

As Diretrizes Curriculares Nacionais para os Cursos de Engenharia de 2019, no que tange as bases para reformulação curricular do Curso de Engenharia Civil, se faz oportuna, concedendo maior autonomia às escolas de engenharia na elaboração de seus currículos, possibilitando uma atualização de seu escopo frente às necessidades de formar um profissional mais autônomo para lidar com relações de trabalho em acentuada transformação, que em decorrência do contexto da crise sanitária imposta pela pandemia do COVID-19, tende a acelerar as transformações que nossa sociedade já enfrentava (informação verbal) ${ }^{3}$.

Observa-se que as novas DCN's trazem consigo uma maior preocupação com a formação de um profissional mais consciente de sua atuação e com um enfoque maior, que a edição anterior, na sustentabilidade ambiental e na responsabilidade social, elementos estes que podem ser possibilitados com o investimento na adoção de métodos de ensino e abordagens dos conteúdos programáticos com a utilização das ferramentas disponíveis no mercado de trabalho como é o caso da plataforma BIM, que fomenta a otimização dos recursos materiais e humanos, no planejamento dos empreendimentos da construção civil.

\footnotetext{
${ }^{2}$ Fala do Eng ${ }^{\circ}$ Civil Luiz Henrique Ceotto, transmissão no instagram, junho de 2020.

${ }^{3}$ Fala do historiador Leandro Karnal, entrevista à CNN, maio de 2020.
} 
Avalia-se que o processo de ensino-aprendizagem e a formação profissional não podem ser pautadas apenas pelas necessidades do mercado, embora seja de grande importância, por ter como finalidade o lucro, concentra-se em avaliar sua conduta de acordo com seu resultado, o que não garante a preocupação de seu método quanto a responsabilidade social, e a sustentabilidade de seus processos, a manutenção da boa técnica, a integridade acadêmica e ética profissional, haja visto que o mercado da construção civil é diversas vezes caracterizado pela informalidade conforme relatou o estudo do CAU.

Ao se buscar o desenvolvimento de competências as Diretrizes Curriculares, submetem às IES, a reconhecer a historicidade do indivíduo, e seu contexto sócio-cultural favorecendo a universalização no acesso ao ensino superior, tratando devidamente a recepção e nivelamento dos discentes, que inclusive está apontado nas diretrizes, enquanto que limitar-se a atender somente as exigências de mercado teria-se, - o que é alertado por Santana (2018) - a facilitação da produção de mão de obra em massa da engenharia, a qual se serviria apenas em realizar tarefas, barateando o valor e preço deste profissional.

Contudo, a academia revestida de responsabilidade de atualizar-se continuamente, diante, do conhecimento e da inovação que ela mesmo enseja, deve formar profissionais com um forte embasamento técnico e alinhado com práticas atuais que por conseguinte acarreta em maior eficiência, rentabilidade e sustentabilidade. A incorporação de tecnologias, não vai substituir a figura do Engenheiro, mas sim potencializar a atividade do Engenheiro, por que esses conceitos se referem a sistemas, e o grande desafio é transformar o sistema num ecossistema dentro da empresa, fazê-los ter utilidade no exercício profissional. (informação verbal) ${ }^{4}$.

Portanto, a adesão ao longo das grades curriculares das ferramentas de projetos alinhadas com as novas tecnologias, favorecem uma visão holística do produto desenvolvido pelo Engenheiro Civil, abarcando toda vida útil dos empreendimentos, além de se mostrar uma ferramenta didática pois favorece a visualização e manipulação dos conceitos vistos em sala de aula por meio da modelagem de seus diversas sistemas, e inclusive evitando interferências que podem ocorrer. Essa prática possibilita um ciclo de projeto menor e mais eficiente, melhor avaliação dos custos e menos desperdício de materiais. O que evidencia a importância da sua utilização e a sua concordância com o que se estabelece as Novas Diretrizes Curriculares Nacionais.

\footnotetext{
${ }^{4}$ Fala do Eng ${ }^{\circ}$ Civil Aldo Dórea Mattos, em palestra na Construsumit, novembro de 2018.
} 


\section{REFERÊNCIAS}

ACCORSSI, Aline, CLASEN, Julia e SILVEIRA, Anelise F. Contribuições críticas sobre a produção científica na atualidade. Conjectura: Filosofia e Educação, Caxias do Sul, v.25, 2020. Disponível em: < http://www.ucs.br/etc/ revistas/index.php/conjectura > Acesso em: 23 jul. 2020.

BASTOS, Priscila. E. de A.; Lordsleem Junior, A. C. O ensino de BIM em curso de graduação em engenharia civil em uma universidade dos EUA: estudo de caso. Ambiente Construído, Porto Alegre, v. 16, n. 4, p. 45-61, out./dez. 2016.

BRASIL. Ministério da Educação. Conselho Nacional de Educação. Câmara de Educação Superior. Resolução n⿳0 2, de 24 de abril de 2019. Institui as Diretrizes Curriculares Nacionais do Curso de Graduação em Engenharia. 2019. Brasília: Ministério da Educação, 2019. Disponível em: http://portal.mec.gov.br/index.php? option=com_docman \&view=download\&alias=112681-rces002-19\&category_slug $=$ abril2019-pdf\&Itemid=30192. Acesso em: 20 jul. 2020.

BRASIL. Ministério da Educação. Conselho Nacional de Educação. Câmara de Educação Superior. RESOLUÇÃO CNE/CES 11, DE 11 DE MARÇO DE 2002 Brasília: Ministério da Educação, $2002 . \quad$ Disponível em <http://portal.mec.gov.br/cne/arquivos/pdf/CES112002.pdf.>Acesso em: 20 jul. 2020.

CAU e DATAFOLHA. O maior diagnóstico sobre a arquitetura e urbanismo já feito no Brasil. Disponível em: <https://www.caubr.gov.br/pesquisa2015/> Acesso em: 25 jul 2020.

CARVALHO, Gisele L. de et. al., A integração das disciplinas de geometria gráfica na engenharia civil através das tecnologias computacionais. Brasilian Journal of Business, Curitiba, v.2. 2020.

EASTMAN, C. et al. Manual de BIM: Um Guia de Modelagem da Informação da Construção. 1 ed. 2013.

LIMA, W.E.F.; MELO, L.A.P.; MELO, R.S.S.; GIESTA, J.P. Interfaces entre o curso de engenharia civil da UFRN e BIM: Uma análise da matriz curricular In: SIMPÓSIO BRASILEIRO DE TECNOLOGIA DA INFORMAÇÃO E COMUNICAÇÃO NA CONSTRUÇÃO, 2., 2019, Campinas, SP. Anais[...] Porto Alegre: ANTAC, 2019. Disponível em: https://antaceventos.net.br/index.php/sbtic/sbtic2019/paper/view/140

MGI - Mckinsey Global Institute. Reinventing construction: a route to higher productivity. Chicago (EUA). 2017.

OLIVEIRA, A. B. de F.; SOUZA, H. A. de. Sistemas construtivos industrializados nos cursos de graduação em engenharia civil e arquitetura do Brasil. Revista de Ensino de $\begin{array}{llllll}\text { Engenharia, } & \text { v. } & 34, & \text { p. } & 53-60, & \text { Disponível }\end{array}$ em: $<$ http://www.abenge.org.br/cobenge/arquivos/5/Artigos/129008.pdf $>$. Acesso em: jan. 2020 .

OLIVEIRA, Fernanda T. de. e SIMÕES, Wagner L. A indústria 4.0 e a produção no context dos estudantes da engenharia. Simpósio de Engenharia de Produção UFG Catalão 2017 
SANTANA, E. ARTIGO: O que muda nos cursos de engenharia com as novas diretrizes curriculares.

Notícias,

2018.

Disponível

em:

https://fisenge.org.br/index.php/noticias/item/5534-artigo-o-que-muda-nos-cursos-deengenharia-com-as-novas-diretrizes-curriculares> Acesso em: 24 jul 2020.

VELASCO, Angela D. Um ambiente multimídia na área de expressão gráfica básica para engenharia. Revista de Ensino de Engenharia, v. 29, n.1 , p-54-61, 2010.

ZANCUL, Eduardo et. al. Estudo sobre produtividade na construção civil: desafios e tendências no Brasil. São Paulo, 2014.

\title{
REFLECTIONS ABOUT THE NEW NATIONAL CURRICULUM GUIDELINES IN CIVIL ENGINEER FORMATION
}

\begin{abstract}
The New National Curriculum Guidelines (DCN's) of Engineering established in 2019, proposes a paradigm shift for the training of students, migrating from a teaching system that sought generalist training, to a holistic training, which presupposes a deeper understanding of the product that is developed by the Engineer through projects. The new DCN's promotes an egress with great technical training and with a dynamic performance and with continuous training, capable of dealing with an efficient labor market promoting sustainable innovations. In this new training reality, it is clear that technologies that were already in vogue, such as the use of the BIM platform and the adoption of new materials, are now aligned with the demands of the construction industry for more productivity and a collective conscience that requires sustainability and social responsibility. This converging the formation of a professional with intellectual autonomy and aware of the social, economic, political and environmental impact on his professional practice.
\end{abstract}

Keywords: Innovation and Sustainability. Curricular Guidelines. Engineering. 